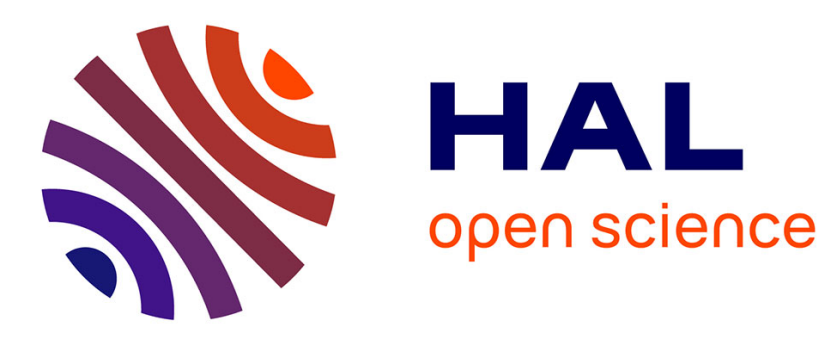

\title{
Effects of aluminium sulphate in the mouse liver: similarities to the aging process
}

\author{
Alessandra Stacchiotti, Antonio Lavazza, Matteo Ferroni, Giorgio \\ Sberveglieri, Rita Rezzani, Luigi Fabrizio Rodella
}

\section{To cite this version:}

Alessandra Stacchiotti, Antonio Lavazza, Matteo Ferroni, Giorgio Sberveglieri, Rita Rezzani, et al.. Effects of aluminium sulphate in the mouse liver: similarities to the aging process. Experimental Gerontology, 2008, 43 (4), pp.330. 10.1016/j.exger.2008.01.009 . hal-00499046

\section{HAL Id: hal-00499046 https://hal.science/hal-00499046}

Submitted on 9 Jul 2010

HAL is a multi-disciplinary open access archive for the deposit and dissemination of scientific research documents, whether they are published or not. The documents may come from teaching and research institutions in France or abroad, or from public or private research centers.
L'archive ouverte pluridisciplinaire HAL, est destinée au dépôt et à la diffusion de documents scientifiques de niveau recherche, publiés ou non, émanant des établissements d'enseignement et de recherche français ou étrangers, des laboratoires publics ou privés. 


\section{Accepted Manuscript}

Effects of aluminium sulphate in the mouse liver: similarities to the aging process

Alessandra Stacchiotti, Antonio Lavazza, Matteo Ferroni, Giorgio Sberveglieri, Rita Rezzani, Luigi Fabrizio Rodella

PII:

S0531-5565(08)00040-5

DOI:

10.1016/j.exger.2008.01.009

Reference:

EXG 8440

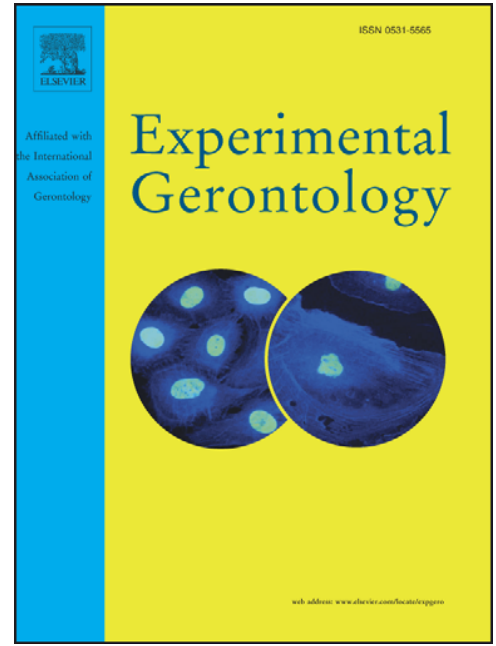

To appear in:

Experimental Gerontology

Received Date:

17 September 2007

Revised Date:

12 December 2007

Accepted Date:

22 January 2008

Please cite this article as: Stacchiotti, A., Lavazza, A., Ferroni, M., Sberveglieri, G., Rezzani, R., Rodella, L.F., Effects of aluminium sulphate in the mouse liver: similarities to the aging process, Experimental Gerontology(2008), doi: 10.1016/j.exger.2008.01.009

This is a PDF file of an unedited manuscript that has been accepted for publication. As a service to our customers we are providing this early version of the manuscript. The manuscript will undergo copyediting, typesetting, and review of the resulting proof before it is published in its final form. Please note that during the production process errors may be discovered which could affect the content, and all legal disclaimers that apply to the journal pertain. 
Effects of aluminium sulphate in the mouse liver: similarities to the aging process

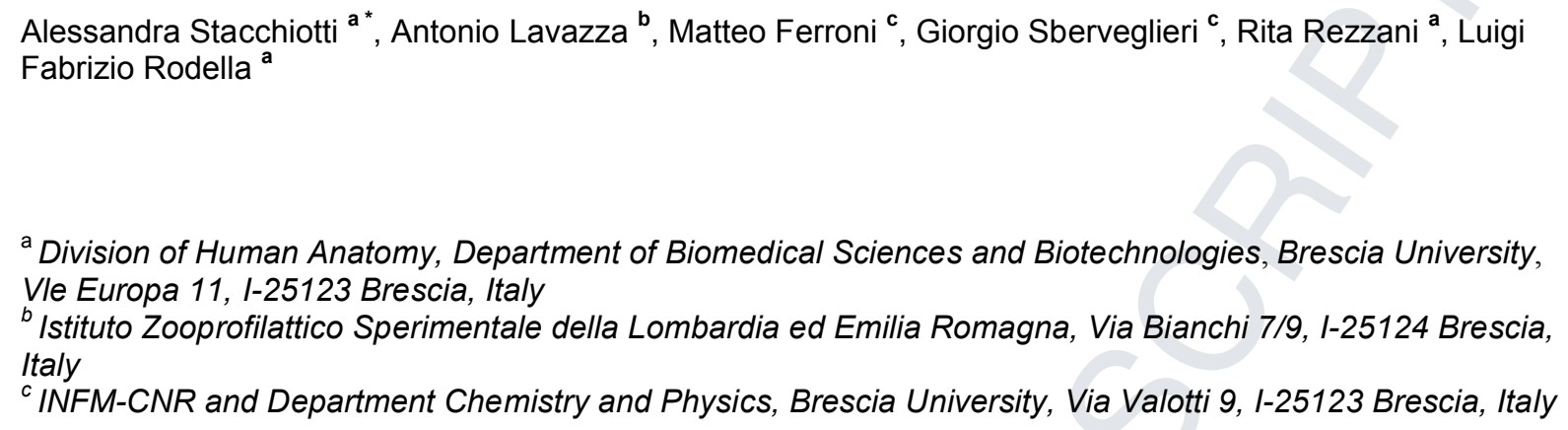

${ }^{a}$ Division of Human Anatomy, Department of Biomedical Sciences and Biotechnologies, Brescia University, Vle Europa 11, I-25123 Brescia, Italy

${ }^{b}$ Istituto Zooprofilattico Sperimentale della Lombardia ed Emilia Romagna, Via Bianchi 7/9, I-25124 Brescia, Italy

${ }^{c}$ INFM-CNR and Department Chemistry and Physics, Brescia University, Via Valotti 9, I-25123 Brescia, Italy

\footnotetext{
${ }^{*}$ Corresponding author: Dr A.Stacchiotti, Tel:+ 39030 3717478; Fax: +39 0303717486.

E-mail address: stacchio@med.unibs.it (Alessandra Stacchiotti)
}

Running title: Aluminium hepatotoxicity and aging

Key words: Liver; Aluminium; Aging; Fibrosis; Ultrastructure; Microanalysis 


\begin{abstract}
Aluminium $(\mathrm{Al})$ is a ubiquitous metal that is potentially toxic to the brain. Its effects on other fundamental organs are not completely understood. This morphological in vivo study sought to compare sublethal hepatotoxic changes and $\mathrm{Al}$ deposition in adult mice that orally ingested $\mathrm{Al}$ sulphate daily for 10 months, in age matched control mice that drank tap water and in senescent mice (24 months old). Livers were examined for collagen deposition using Sirius red and Masson, for iron accumulation using Perls' stain. Light, electron microscopy and morphometry were used to assess fibrosis and vascular changes. Scanning transmission electron microscopy and EDX microanalysis were used to detect in situ elemental Al. Iron deposition, transferrin receptor expression were significantly altered following $\mathrm{Al}$ exposure and in the aged liver but were unaffected in age matched control mice. In Al treated mice as in senescent mice, endothelial thickness was increased and porosity was decreased like perisinusoidal actin. Furthermore, Al stimulated the deposition of collagen and laminin, mainly in acinar zones 1 and 3 . Pseudocapillarization and periportal laminin in senescent mice were similar to Al treated adult liver. In conclusion, prolonged Al sulphate intake accelerates features of senescence in the adult mice liver.
\end{abstract}


Humans are uniformly exposed to $\mathrm{Al}$ that is present in the soil, food and drinking water (Flaten, 2001). $\mathrm{Al}$ is potentially neurotoxic although its biological effects are not yet well known (Walton, 2007). There are several data linking elevated $\mathrm{Al}^{3+}$ levels to neurological pathologies such as multiple sclerosis, Guam Parkinson dementia, Parkinson's disease and Alzheimer's disease (Nayak, 2002). Prolonged Al exposure accelerates ageing changes in the adult rat brain (Deloncle et al., 2001) and enhanced Al deposition in the brain is a shared characteristic of progressive neurological diseases that are common in aged populations (Miu et al., 2004). The deposition of Al in non nervous organs and its subsequent effects are less known. We previously described the effects of $\mathrm{Al}$ in the rat kidney and liver, where it induces lysosomal activation and increases iron deposition (Stacchiotti et al., 2006).

So here we focused again on the liver due to its involvement in Al absorption and excretion through biliary flux (Gonzales et al., 2007). Once in the liver Al increases cells' iron uptake and oxidative status (Perez et al., 2005). Besides the spleen, the liver is the chief site of iron storage, containing $98 \%$ of total iron and a large abundance of transferrin receptors (TfRs). Synthesis of the TfR, a glycoprotein that binds the diferric transferrin molecule, is highly regulated by iron (Rimon et al., 2002). Al has pro-oxidative effects in vitro and in vivo (Exley, 2004). It produces toxic effects by modifying iron homeostasis and interfering with iron regulatory proteins (Kim et al., 2007) and in several tissues Al content is associated to elevations of iron (Ward et al., 2001; Ohtsuki et al., 2008).

The overall purpose of this microscopic study was to identify similarities between the effects of prolonged oral Al intake (10 months) and aging on the mouse liver. In particular we focused on changes in sinusoidal endothelial cells and in the perisinusoidal space of Disse.

Our major goals were: 1) to analyze hepatic iron and collagen deposition using histopathology; 2) to assess Ito stellate cells (HSCs) granulation, endothelium thickness, porosity, the space of Disse width and microvillar projections using light and transmission electron microscopy and morphometry; 3 ) to investigate the distribution of TfR, actin, as a marker associated to endothelial fenestrae (Braet and Wisse, 2002) and laminin, a glycoprotein of basement membranes, using immunohistochemistry; and 4) to identify Al in situ using EDX microanalysis and low voltage STEM microscopy.

\section{Materials and methods}

2.1. Animals and treatments 
Male C57BL/6 mice (Harlan Italy, Milan, Italy) were used in this study. The animals were housed in groups in

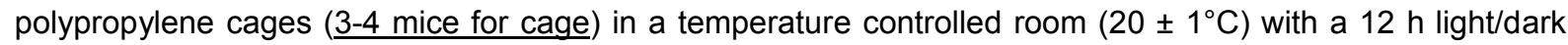
cycle. Standard Vogt Moller rodent diet containing $150 \mathrm{mg} / \mathrm{kg}$ iron (Laboratory Dott.Piccioni, Milan, Italy) and fresh tap water were provided ad libitum. Animals were divided into three groups. In the aluminium treated group 1: eight $(n=8)$ adult animals received $2.5 \%$ aluminium sulphate dissolved in tap water (Sigma, St. Louis, MO, USA) (Hermenegildo et al., 1999) via polypropylene bottles with a stainless steel tops for 10 months. An age matched control group 2: six mice $(n=6)$ housed in similar conditions and administered plain tap water for 10 months. Group 3 senescent control mice: six $(n=6)$ C57BL/6 mice (24 months old $)$ were also administered plain tap water. Every effort was made to minimize animal suffering according to Italian law on the protection of laboratory animals. All experimental procedures were approved by the Italian Ministry of Health.

\subsection{Tissue preparation}

Mice were anaesthetised with sodium pentobarbitone $(50 \mathrm{mg} / \mathrm{kg}$ i.p.) and perfused with fresh $4 \%$ paraformaldehyde in phosphate buffered saline (PBS) using a 23G needle inserted into the ascending aorta. Livers were immediately extracted and minced. Pieces intended for electron microscopy were additionally fixed in $2.5 \%$ glutaraldheyde in PBS and post fixed in osmium tetroxide $1 \%$ in PBS for $1 \mathrm{~h}$ at $4{ }^{\circ} \mathrm{C}$.

\subsection{Light microscopy histochemistry and immunohistochemistry}

Samples were dehydrated in ethanol and embedded in paraffin (Paraplast, BDH). Sections $(4 \mu \mathrm{m}$ thick), collected on poly L Iysine coated glass slides (Sigma Aldrich, Milan, Italy), were stained by H\&E to determine the mitotic index and lymphocyte infiltration. Sirius red staining was used to identify fibrosis and collagen deposition by light microscope equipped with a polarized filter (Olympus). Type I thick collagen fibres were detected as yellow or red, whereas type III thin collagen fibres appeared green. In addition, iron deposition was examined using Perl's staining on adjacent sections. The distributions of laminin, TfR and actin were determined by $A B C$ peroxidase method as previously reported (Stacchiotti et al., 2006a). Sections were incubated at $4^{\circ} \mathrm{C}$ overnight with the following primary antibodies: a rabbit polyclonal antibody against mouse laminin from Englebreth Holm Swarm sarcoma (1:50; Sigma), a mouse monoclonal antibody against recombinant human TfR that cross reacts with mouse TfR (1:250; Zymed Laboratories), and a mouse monoclonal antibody against chicken actin that cross reacts with actins from all vertebrates (1:250; Chemicon). All stainings were graded semiquantitatively according to intensity staining in different lobular zones (Malarkey et al., 2005). Moreover Sirius red and TfR and actin immunostainings were also evaluated 
by quantitative image analysis. Images were aquired by a digital microscope (Olympus, Germany) equiped with an image analyzer (Image Pro Plus, Milan, Italy) and labelling intensity was computed as IOD (integrated optical density) according to previously reported (Stacchiotti et al., 2006 b).

\subsection{Electron microscopy}

Livers were trimmed and pieces dehydrated in ethanol, propylene oxide and embedded in araldite resin (Serva). Semithin (1 $\mu \mathrm{m}$ thick) sections, collected on glass slides, were stained using a mixture of Azur II and methylene blue to detect Ito stellate cells (HSCs); HSCs granules density and area were determined using high resolution light microscopy (X 100) and the Image Pro Plus program (Media Cybernetics Inc.). For transmission electron microscopy, ultrathin sections $(70-80 \mathrm{~nm}$ thick) obtained from zone 3 and zone 1 were collected on a formvar coated 200 mesh copper grid, stained with uranyl acetate and lead citrate, and photographed using a TEM CM10 Philips at $80 \mathrm{kV}$. Endothelial thickness, the number of fenestrations (porosity), the width of the space of Disse, and the density of microvillar projections were estimated by point counting (Cogger et al., 2001). For microanalysis, we obtained $0.1 \mu \mathrm{m}$ thick sections using diamond glass (Microstar), collected on 300 mesh nickel grids without formvar and stained by uranyl acetate. To avoid sample contamination we used only plastic materials left in a $1: 9 \mathrm{HNO}_{3} /$ ethanol mixture at least $48 \mathrm{~h}$, as per Pimentel Vieira et al. (2000). We analyzed samples using a LEO 1525 SEM FEG microscope operated at 16-20 kV equipped with a STEM detector.

\subsection{Statistical analyses}

Each experiment was performed in triplicate for each animal. Data are presented as the mean \pm SEM. Differences were evaluated by ANOVA with Bonferroni correction. Statistical significance was set at $P<0.05$ and $\mathrm{P}<0.01$.

\section{Results}

\subsection{Animals}

The average body weight of adult mice at the beginning was $20 \pm 3 \mathrm{~g}$. After 10 months, the average body weight was not significantly different between Al treated mice and the control group ( $32 \pm 4 \mathrm{~g}$ vs $30 \pm 4 \mathrm{~g}$ ). Mean daily intake of water was $3.8 \pm 2.9 \mathrm{ml} /$ mouse for the Al treated group and $4 \pm 2.4 \mathrm{ml} /$ mouse for the age matched control and senescent groups. All animals survived. No specific behavioural tests were performed but, after 10 months, no group differences in behaviour were observed (Platt, 2006). 


\subsection{Histopathology and immunohistochemistry}

H\&E staining did not reveal any necrosis in the liver parenchyma at 10 months Al intake and the mitotic index was not statistically different between groups. Vacuolation and steatosis were scarce in senescent, $\mathrm{Al}$ treated and age matched controls (data not shown). Sirius red demonstrated limited perisinusoidal fibrosis in age matched controls, whereas such fibrosis was evident in both Al treated and senescent mice (Fig.1). Polarized microscopy showed few perisinusoidal (yellow or red) new collagen type I fibres in age matched controls (Fig.1). The staining was more intense after Al intake (Fig.1C). In senescent mice, yellow and constitutive green thin collagen type III fibres were present (Fig.1B).

Figure 1 here

Quantitative evaluation of Sirius red staining was randomly made for all sections and perisinusoidal collagen deposition significantly enhanced in Al exposed and aged mice (mean percentage $2.5 \pm 0.2$ and $2.1 \pm 0.3$ ) versus adult controls $(1.6 \pm 0.2)$.

Iron hemosiderin Prussian blue deposits were negligible in age matched controls but intense in the cytoplasm of hepatocytes after Al treatment and in non parenchymal cells lining the sinusoidal space in the senescent group (Fig.2). Masson staining clearly marked fibrosis around portal space in mice after Al intake for 10 months (Fig.2 E) and in aged group (Fig.2 F) but reduced in adult controls (Fig.2 D).

Figure 2 here

Laminin was undetectable in age matched controls and scarce in senescent livers, where the portal zone was faintly stained (Fig.3). In contrast, after Al treatment, the laminin signal was evident above vessels in all lobular zones (Fig.3). TfR immunostaining was moderate and restricted to the hepatocytes boundary in adult controls (Fig.3). In Al treated mice, the staining was more diffuse and detected also in the Kupffer cells (Fig.3). In the senescent group, TfR staining was often detached from the sinusoidal side of hepatocytes and scattered in the cytoplasm (Fig.3). Actin was uniformly distributed in the lobule along the perisinusoidal side of adult controls, but more faint in Al-treated and in senescent livers (Fig.3). Quantitative data on TfR and actin immunostainings evaluated with respect to the lobular zone are summarized in Figure $4 . \underline{\mathrm{Al} \text { intake }}$ enhanced TfR in the liver and a similar trend was detected for aged mice while perisinusoidal actin significantly decreased in Al treated and aged mice respect to adult controls.

Figure 3 here

Figure 4 here 


\subsection{High resolution light and transmission electron microscopy}

In semithin sections from adult livers we observed normal multi granulated HSCs lining the perisinusoidal space, whereas after Al exposure there were fewer HSC granules but they were larger as in senescent livers (Fig.5). The percentage of HSCs containing a single granule was higher in Al treated mice $(17 \pm 2 \%)$ and senescent mice $(19 \pm 2 \%)$ compared to age matched controls $(8 \pm 2 \%)$. In contrast, there were $10-20 \%$ fewer multi granulated HSCs in the Al treated mice and senescent mice relative to age matched controls. Ultrastructural analysis revealed a normal space of Disse in controls, whereas after Al exposure it was widened, with reduced hepatocytes projections, filled with collagenous debris (Fig.5). Furthermore, while in age matched controls the sinusoidal endothelium was devoid of a basal lamina, in the Al group it was thickened with a basal lamina, focal coalescence of pinocytotic vescicles and atypical erythrocytes in the lumen (Fig.5). Table 1 summarizes morphometric electron microscopy findings, including endothelial thickness, width of the space of Disse, "porosity" (the percentage of the endothelial surface with fenestrations), and density of hepatocytes projections. Many parameters were similar in the livers of $\mathrm{Al}$ treated and senescent mice. However, relative to the control group, the space of Disse was 40 to $70 \%$ wider, and the porosity and microvillar projections 60 to $80 \%$ reduced.

\section{Figure 5 here}

\subsection{STEM microscopy and microanalysis}

STEM microscopy at low voltage in livers from Al treated mice showed electron dense particles in a fibroblast like-cell lining the space of Disse but no Al deposition inside the hepatocytes (ig.6). At higher magnification, the Al particles resembled multiple aggregates inside the cytoplasm. The compositional EDX microanalytical spectrum of the particles revealed 2 distinct new peaks of elemental aluminium/osmium and magnesium (Fig.7). In a subsequent $100 \mathrm{~nm}$ thick section, no such deposits were present in the same field (Fig.6), and the relative EDX spectrum was clearly devoid of Al (ig.7). No similar particles were detected in the liver of age matched controls or senescent mice.

Figure 6 here

Figure 7 here

\section{Discussion}

In this in vivo morphological study, several similarities were found between C57BL/6 mouse livers exposed to Al sulphate for 10 months and senescent C57BL/6 mouse livers. It is known that Al body burden increased 
in ageing and causes oxidative damage (Exley, 2004). Total iron accumulation and anaemia are increased in the elderly and in experimentally aged animals (Levenson and Tassabehji, 2004). During ageing of the liver, besides parenchymal cells (reviewed by Schmucker, 1990), morphological changes involved the endothelium, bile duct cells and non parenchymal cells (Kmiec, 2001; Schmucker, 2005). In particular, alterations in microvascular hemodynamic in rats (Vollmar et al., 2002) and age related sinusoidal thickening ("pseudocapillarization" ) has been reported in humans (Mc Lean et al., 2003), rats (Le Couter et al., 2001), and mice (Warren et al., 2005; Ito et al., 2007).

Remarkably here, after Al intake for 10 months, we observed in mice liver enhanced endothelial thickness and reduced porosity, together with reduced perisinusoidal actin that confirmed Al induced defenestration. Reduced endothelial porosity, together with abnormalities of collagen accumulation, and deposition of the basal lamina components, may affect lipoproteins transport (Hilmer et al., 2005). In Al treated mice, basal lamina deposition in the sinusoids was outlined by laminin immunohistochemistry. The sinusoidal side of hepatocytes, and in particular the space of Disse, are the choice sites for Al intake from the portal blood circulation (De Voto and Yokel, 1994). Here, using EDX microanalysis, we found Al in the sinusoidal side of a fibroblast lining the space of Disse. This finding supports the hypothesis that an ultrafiltration mechanism is involved in the Al uptake in the liver (Warren et al., 2005). Kametani and Nagata (2005) previously reported Al in the livers of mice drinking Al chloride. Using EDX microanalysis and high voltage electron microscopy they demonstrated $\mathrm{Al}$ in both hepatocytes and macrophages. In contrast, we did not find Al inside the hepatocytes: this is probably due to differences in technique or in Al salts. Likely for these reasons, we were unable to find $\mathrm{Al}$ in the senescent liver, although Al has been identified in aging lipofuscin pigment (Seehafer and Pearce, 2006). Another relevant morphological finding is the reduced number but larger size of granules in Ito stellate cells (HSCs) following chronic Al ingestion. This is probably due to a major deposition of vitamin A metabolites, which is also typical of aging. With regards to collagen, we detected and quantitated more collagen deposition and fibrosis in both aged and Al treated adult mice in perisinusoidal side along all lobules and around the portal space. HSCs and endothelial cells are the major sites of laminin deposition, and remarkably, we described the presence of laminin above the sinusoids and in the portal area in livers from Al treated and senescent mice but not in livers from age matched controls. Pseudocapillarization, defenestration and the major deposition of lamin in the basal membrane are early markers that precede more severe damage in the liver .

We demonstrated also that in the livers of Al treated and senescent mice iron metabolism was affected as reflected by Perls' and TfR distribution. In a previous study, after 3 months of Al administration, both iron and 
ferritin deposition were increased (Turgut et al., 2004); we obtained the same finding after more prolonged exposure. TfR pattern was very similar in the livers of Al treated and senescent mice, scattered in the cytoplasm sometimes detached from the sinusoidal side compared to age matched controls. When we further examined the overall quantitative distribution of the TfR in different lobular zones, after Al the signal enhanced like in aged mice but was more limited in adult controls. Moreover, Perl's staining revealed increased iron in hepatocytes in the Al treated group and in Kupffer cells in the senescent group. Our findings are consistent with those of Sciot et al. (1990), who reported an inverse relationship between iron deposition and TfR distribution. Furthermore, the presence of iron differs across acinar zones (Malarkey et al., 2005), and this trend is also maintained by the TfR pattern. A recent histopathological study confirmed the strict presence and association of both $\mathrm{Al}$ and iron in pulmonary tissue in humans occupationally exposed to heavy metals (Ohtsuki et al., 2008).

Together, these results support the hypothesis that prolonged Al intake accelerates the aging process in the liver. 


\section{Acknowledgements}

We thank G. Bertocchi and G. Bozzoni for skilled electron microscopy, Dr. E. Foglio for the immunohistochemistry, and N. Pedretti for the histochemistry and sectioning of STEM samples. The suggestions and encouragements of Prof. C.Exley, Keele University (U.K.), have been kindly appreciated. The study was supported by local institutional grants (ex 60\% 2006-2007 AS). 


\section{References}

Braet, F. and Wisse, E., 2002. Structural and functional aspects of liver sinusoidal endothelial cell fenestrae: a review. Comp. Hepatol. 1, 1-17.

Cogger, V., Mross, P., Hosie, M., Ansselin, A., McLean, A., Le Couter, D., 2001. The effect of acute oxidative stress on the ultrastructure of the perfused rat liver. Pharmacol. Toxicol. 89, 306-311.

De Voto, E., Yokel, R., 1994. The biological speciation and toxicokinetics of aluminum. Env. Health Perspect. $102,940-951$

Deloncle, R., Huguet, F., Fernandez, B., Quellard, N., Babin, P., Guillard, O., 2001. Ultrastructural study of rat hippocampus after chronic administration of aluminum L-glutamate: an acceleration of the aging process. Exp.Gerontol. 36, 231-244.

Exley, C., 2004. The pro-oxidant activity of aluminium. Free Radic. Biol. Med. 36, 380-387.

Flaten, T., 2001. Aluminium as a risk factor in Alzheimer's disease, with emphasis on drinking water. Brain Res.Bull. 55, 187-196.

Gonzales, M., Alvarez Mdel, L., Pisani, G., Bernal, C., Roma, M., Carrillo, M., 2007. Involvement of oxidative stress in the impairment in biliary secretory function induced by intraperitoneal administration of aluminium to rats. Biol. Trace Elem. Res. 116, 329-342.

Hermenegildo, C., Saez, R., Minoia, C., Manzo, L., Felipo, V., 1999. Chronic exposure to aluminium impairs the glutamate-nitric oxide-cyclic GMP pathway in the rat in vivo. Neurochem. Int. 34, 245-253.

Hilmer, S., Cogger, V., Fraser, R., Mc Lean, A., Sullivan, D., Le Couter, D., 2005. Age-related changes in the hepatic sinusoidal endothelium impede lipoprotein transfer in the rat. Hepatology 42, 1349-1354.

Ito, Y., Sorensen, K., Bethea, N., Svistounov, D., Mc Cuskey, M., Smedsrod, B., Mc Cuskey, R., 2007. Agerelated changes in the hepatic microcirculation in mice. Exp Gerontol. 42, 789-797.

Kametani, K., Nagata, T., 2006. Quantitative elemental analysis on aluminium accumulation by HVTEM-EDX in liver tissues of mice orally administered with aluminium chloride. Med. Mol. Morphol. 39, 97-105.

Kim, Y., Olivi, L., Cheong, J., Maertens, A., Bressler, J., 2007. Aluminium stimulates uptake of nontransferrin bound iron and transferrin bound iron in human glial cells. Toxicol Appl Pharmacol. 220, 349-356. Kmiec, Z., 2001. Cooperation of liver cells in health and disease. Adv. Anat. Embryol. Cell. Biol. 161, 1-151. Le Couter, D., Cogger, V., Markus, A., Harvey, P., Yin, Z., Ansselin, A., McLean, A., 2001. Pseudocapillarization and associated energy limitation in the aged rat liver. Hepatology 33, 537-543. Levenson, C., Tassabehji, N., 2004. Iron and ageing: an introduction to iron regulatory mechanisms. Ageing Res. Rev. 3, 251-263. 
Malarkey, D., Johnson, K., Ryana, L., Boorman, G., Maronpot, R., 2005. New insights into functional aspects of liver morphology. Toxicol. Pathol. 33, 27-34.

Mc Lean, A., Cogger, V., Chong, G., Ewarren, A., Markus, A., Dahlstrom, J., Le Couter, D., 2003. Agerelated pseudocapillarization of the human liver. J. Pathol. 200, 112-117.

Miu, A.C., Olteanu, A., Miclea, M., 2004. A behavioural and ultrastructural dissection of the interference of aluminium with aging. J. Alzheimers Dis. 6, 315-328.

Nayak, P., 2002. Aluminum: impacts and disease. Environ.Res. 89, 101-115.

Ohtsuki, Y., Yamanaka, A., Ohyama, H., Yamada, E., Terada, N., Fujita, J., Lee, G., Furihata, M., 2008. Histochemical demonstration of aluminum and iron deposition in pulmonary bony tissues in three cases of diffuse pulmonary ossification. Histology Histopathology 23, 137-141.

Perez, G., Pregi, N., Vittori, D., Di Risio, C., Garbossa, G., Nesse, A., 2005. Aluminium exposure affects transferrin-dependent and -independent iron uptake by K562 cells. Biochim. Biophys. Acta 1745, $124-130$. Pimentel Vieira, V., Teixeira Rocha, B., Schetinger, M., Morsch, V., Rodrigues, S., Moreira Tuerlinckz, S., Bohrer, D., Do Nascimento, P., 2000. Effect of aluminum on $\delta$-aminolevulinic acid dehydratase from mouse blood.Toxicol Lett. 117, 45-52.

Platt, B., 2006. Experimental approaches to assess metallotoxicity and ageing in models of Alzheimer's disease. J Alzheimers Dis. 10, 203-213.

Rimon, E., Levy, S., Sapir, A., Gelzer, G., Peled, R., Ergas, D., Sthoeger, Z., 2002. Diagnosis of iron deficiency anemia in the elderly by transferrin receptor-ferritin index. Arch.Intern.Med. 162, 445-449.

Schmucker, D., 1990. Hepatocyte fine-structure during maturation and senescence. J Electron Microscopy Tech. $14,106-125$.

Schmucker, D., 2005. Age-related changes in liver structure and function: implications for disease? Exp.Gerontol. 40, 650-659.

Sciot, R., Verhoeven, G., Van Eyken, P., Cailleau, J., Desmet, V., 1990. Transferrin receptor expression in rat liver: immunohistochemical and biochemical analysis of the effect of age and iron storage. Hepatology $11,416-427$

Seehafer, S., Pearce, D., 2006. You say lipofuscin, we say ceroid: Defining autofluorescent storage material. Neurobiol. Aging 27, 576-588.

Senoo, H., 2004. Structure and function of hepatic stellate cells. Med. Electron. Microsc. 37, 3-15. 
Stacchiotti, A., Rodella, L.F., Ricci, F., Rezzani, R., Lavazza, A., Bianchi , R., 2006 a. Stress proteins expression in rat kidney and liver chronically exposed to aluminium sulphate. Histol. Histopathol. 21, 131140.

Stacchiotti, A., Ricci, F., Rezzani ,R., Li Volti, G., Borsani, E., Lavazza,A., Bianchi, R., Rodella, L.F., 2006 b. Tubular stress proteins and nitric oxide synthase expression in rat kidney exposed to mercuric chloride and melatonin. J Histochem Cytochem 54, 1149-1157.

Turgut, G., Kaptanoglu, B., Turgut, S., Enli, Y., Genc, O., 2004. Effects of chronic aluminum administration on blood and liver iron-related parameters in mice. Yonsei Med.J. 45, 135-139.

Vollmar, B., Pradarutti, S., Richter, S., Menger, M., 2002. In vivo quantification of ageing changes in the rat liver from early juvenile to senescent life. Liver 22, 330-341.

Walton, J., 2007. A longitudinal study of rats chronically exposed to aluminium at human dietary levels. Neurosci. Lett. 412, 29-33.

Ward, R., Zhang, Y., Crichton, R., 2001. Aluminium toxicity and iron homeostasis. J. Inorg. Biochem. 87, 914.

Warren, A., Bertolino, P., Cogger, V., Mc Lean, A., Fraser, R., Le Couter, D., 2005. Hepatic pseudocapillarization in aged mice. Exp.Gerontol. 40, 807-812. 


\section{Figure Legends}

Fig.1. Liver from aged (24 months, $A, B)$, adult $A l$ treated $(C, D)$ and age matched control $(E, F)$ mice.

Sirius red $(A, C, E)$ and polarized microscopy $(B, D, F)$ show perisinusoidal staining and collagen deposition in senescent and Al treated groups (original magnification X 400).

Fig.2. Liver from adult (A), Al treated (B) and aged (24 months, C) mice. The tissue has been stained by Perl's (A-C) and by Masson trichrome (D-E). Both in senescent and mice that drank Al there are intense blue iron deposits $(\rightarrow)$ and evident periportal fibrosis. Original magnification X 200 D-E; X 400 A,B; X 1000 C.

Fig.3. Immunohistochemistry of laminin $(A, B, C), \quad T f R(D, E, F)$ and actin $(G, H, I)$ in the liver of adult control, $A I$ treated and senescent mice. (A) Undetectable laminin staining in the controls. (B) Perisinusoidal laminin staining $(\rightarrow)$ after Al intake. (C) Faint laminin staining $(\rightarrow)$ in senescent liver. (D) In zone 3 TfR was membrane bound in age matched group. (E) TfR was moderate in the cytoplasm in the same zone in Al group. (F) Cytoplasmic TfR staining in aged liver. (G) Evident perisinusoidal actin in adult controls. (H) Weak perisinusoidal actin in Al treated and in senescent mice ( I ). Original magnification X $20 \mathrm{G}, \mathrm{H}, \mathrm{I}$; X 400, $A, D, E, F ; X 1000 B$ and $C$.

Fig.4. Optical density analysis (IOD) of TfR (A, B) and actin (C) in different acinar zones. Enhanced TfR pattern in Al treated and in aged mice and reduced perisinusoidal actin signal in respect to adult controls. * significant $P<0.05$ versus adult controls.

Fig.5. High resolution light and electron microscopy of the liver.

Semithin sections (original magnification X1 000) show multi granulated HSCs in controls (A), single granulated HSCs in Al group (B). Ultrastructure of the liver shows regular feature in adult controls. Original magnification X 5200 (C), widened Disse space (ds) in Al treated mice with fibrotic debris (D). The sinusoidal endothelium (se) and Disse space (ds) were normal in controls (E). The sinusoidal endothelium (se) showed irregular thickness and clustered pinocytotic vesicles $(\rightarrow)$ after Al intake $(F)$. Original magnification $\times 28500$.

Fig.6. STEM microscopy of the Disse space in Al treated mice.

A fibroblast-like cell (inside a square) in the fibrotic liver ( $\underline{A})$. In this cell we observed scattered electron dense particles (white arrows) (B). At higher resolution these particles were polymeric and located in the cytoplasm $(\underline{\mathrm{C}})$. The same cell, in a subsequent section, devoid of elemental aluminium (ㅁ) .

Fig.7. Microanalysis of the Disse space in Al treated mice.

EDX spectrum (yellow 1) of the particles shown in figure 6 B and $C$ presented aluminium/osmium and magnesium peaks $(\rightarrow)$. Such peaks are not visible in the EDX spectrum (red 4) of cell shown in figure 6D. 
Table 1

Morphometric data on adult liver treated by $\mathrm{Al}$, age matched and senescent C57BL/6 mice

\begin{tabular}{|c|c|c|c|}
\hline & $\begin{array}{l}\text { Age matched } \\
(n=6)\end{array}$ & $\begin{array}{l}\text { Al treated } \\
(n=8)\end{array}$ & $\begin{array}{l}\text { Senescent mice } \\
(n=6)\end{array}$ \\
\hline $\begin{array}{l}\text { Endothelial } \\
\text { thickness } \\
(\mu \mathrm{m})\end{array}$ & $160 \pm 7$ & $258 \pm 8$ * & $247 \pm 11$ * \\
\hline $\begin{array}{l}\text { Porosity } \\
\text { ( Fenestrations per } \\
10 \mu \mathrm{m} \text { of } \\
\text { endothelium) }\end{array}$ & $2.1 \pm 1.1$ & $0.6 \pm 0.5$ * & $0.7 \pm 0.6$ * \\
\hline $\begin{array}{l}\text { Space of Disse } \\
\text { width }(\mu \mathrm{m})\end{array}$ & $413 \pm 10$ & $497 \pm 16$ * & $512 \pm 12$ * \\
\hline $\begin{array}{l}\text { Projections density } \\
(\%)\end{array}$ & $60 \pm 2$ & $44 \pm 2$ * & $36 \pm 3$ ** \\
\hline
\end{tabular}




\section{Figure(s)}
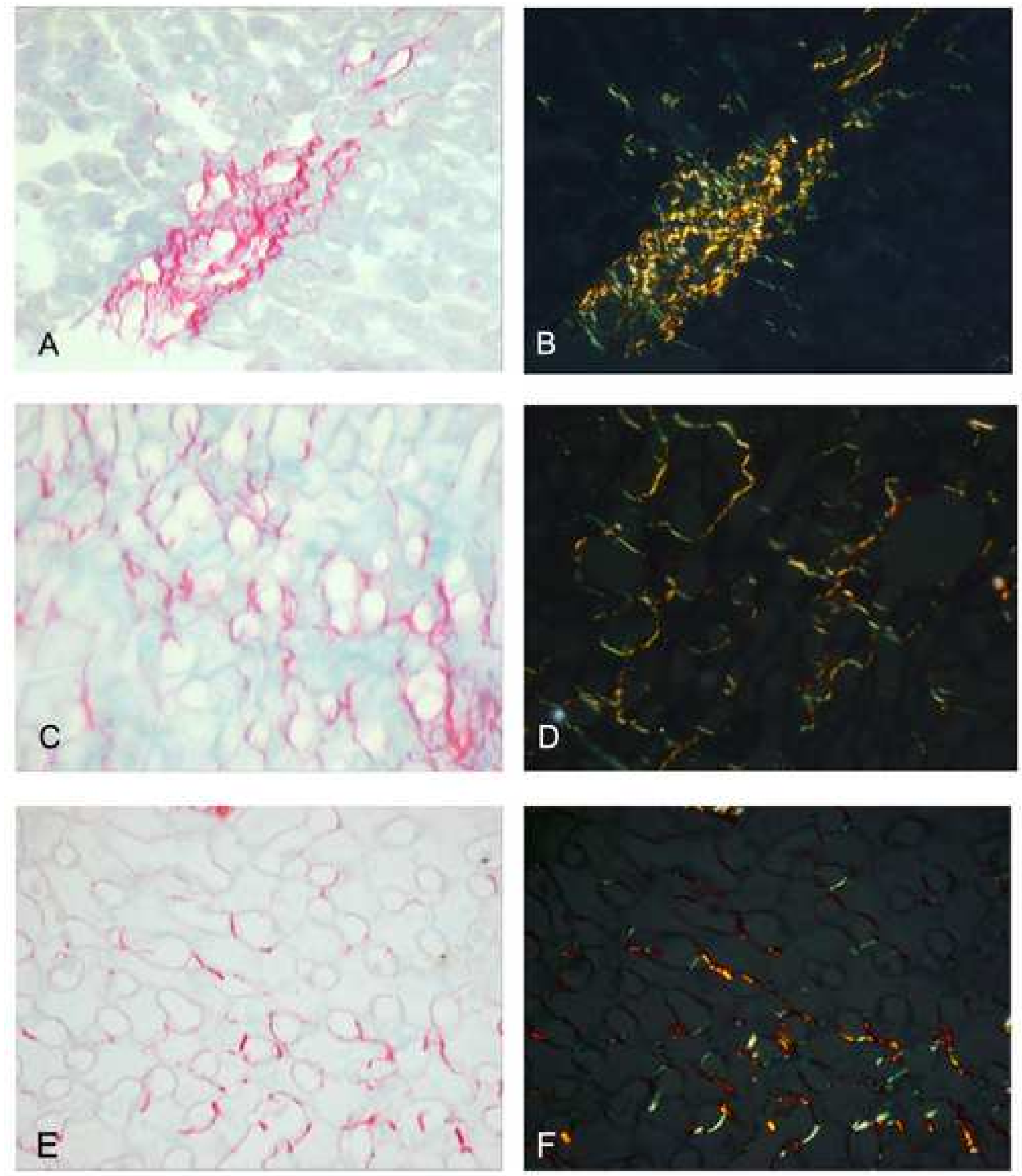

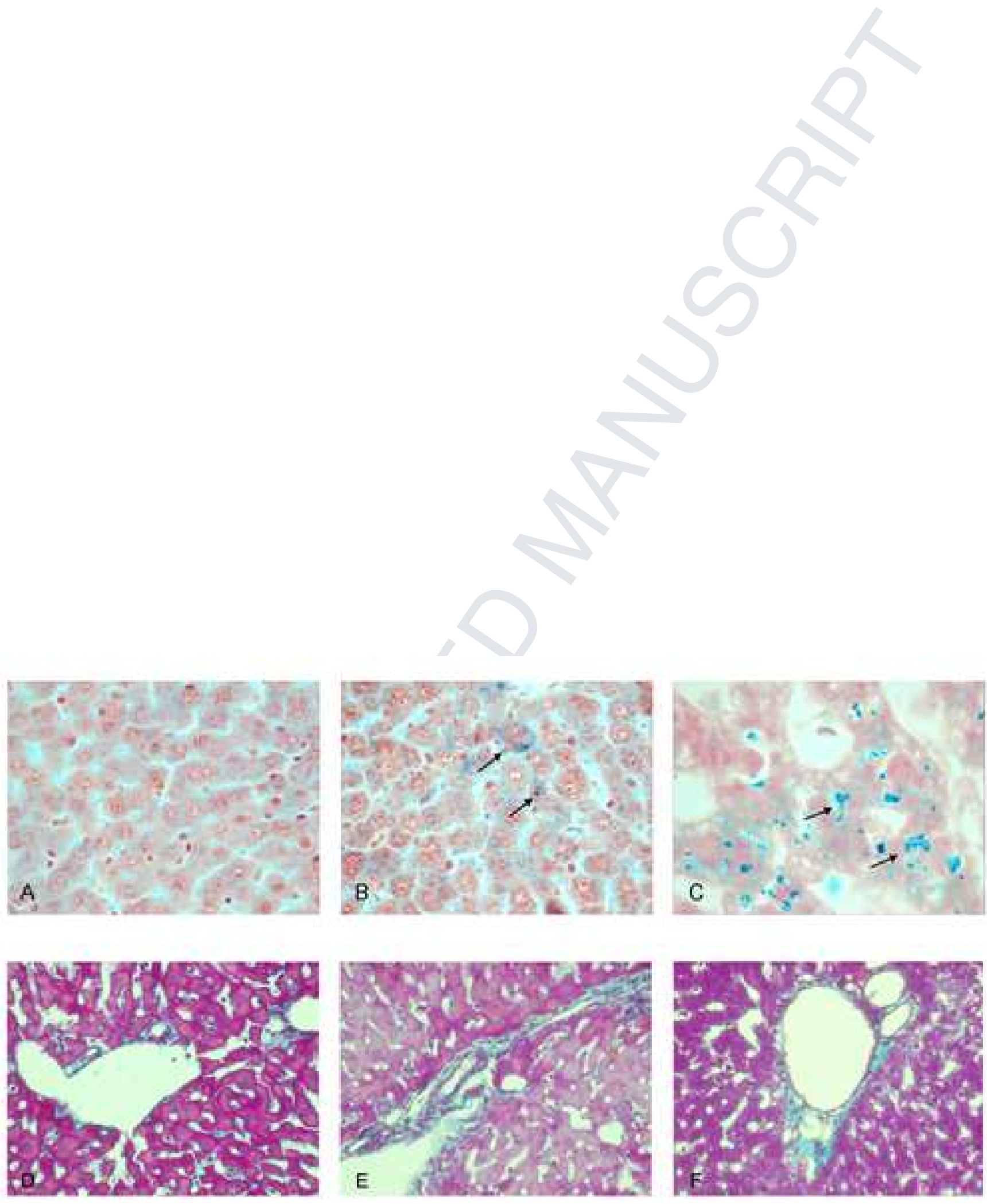

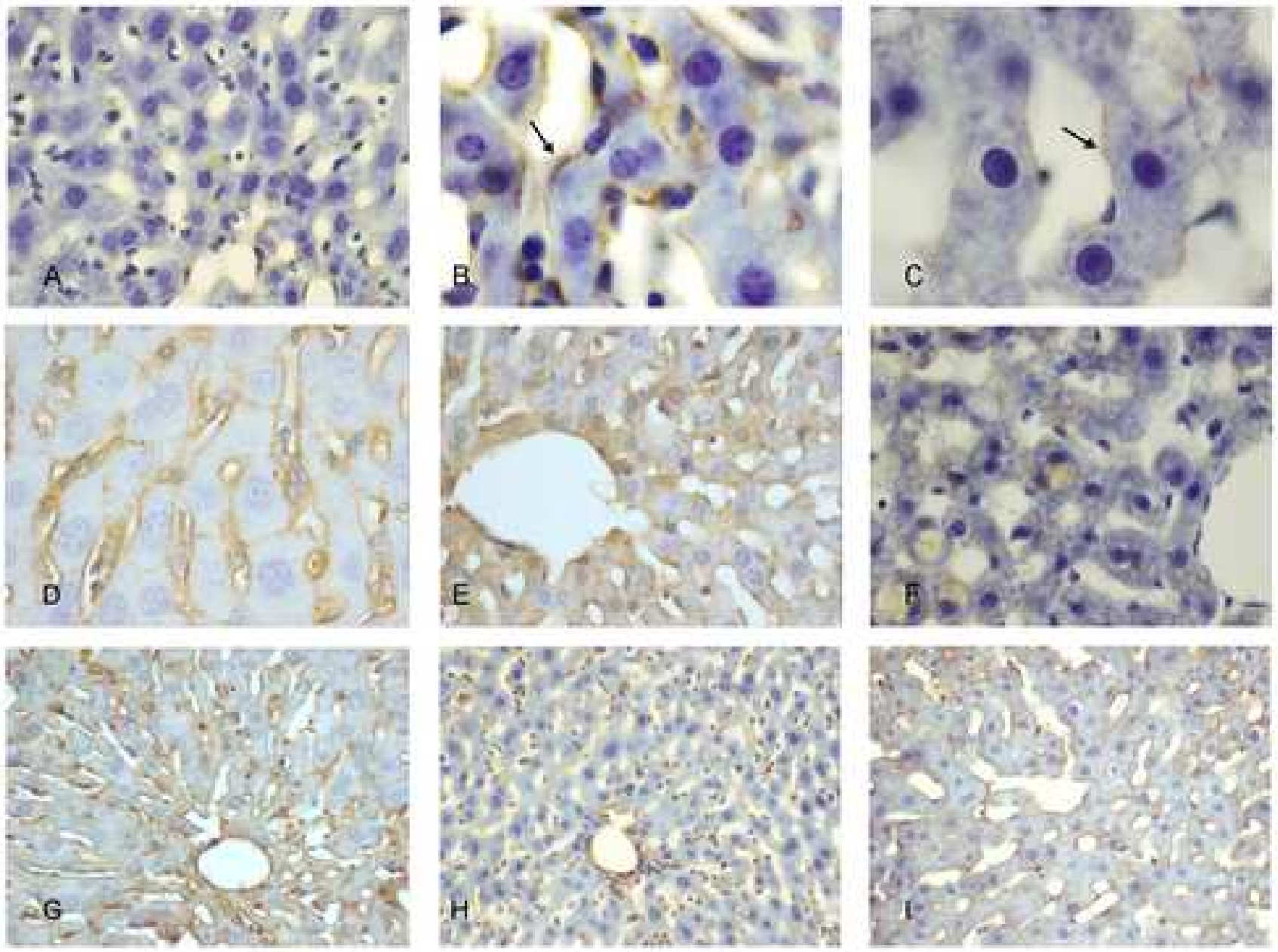


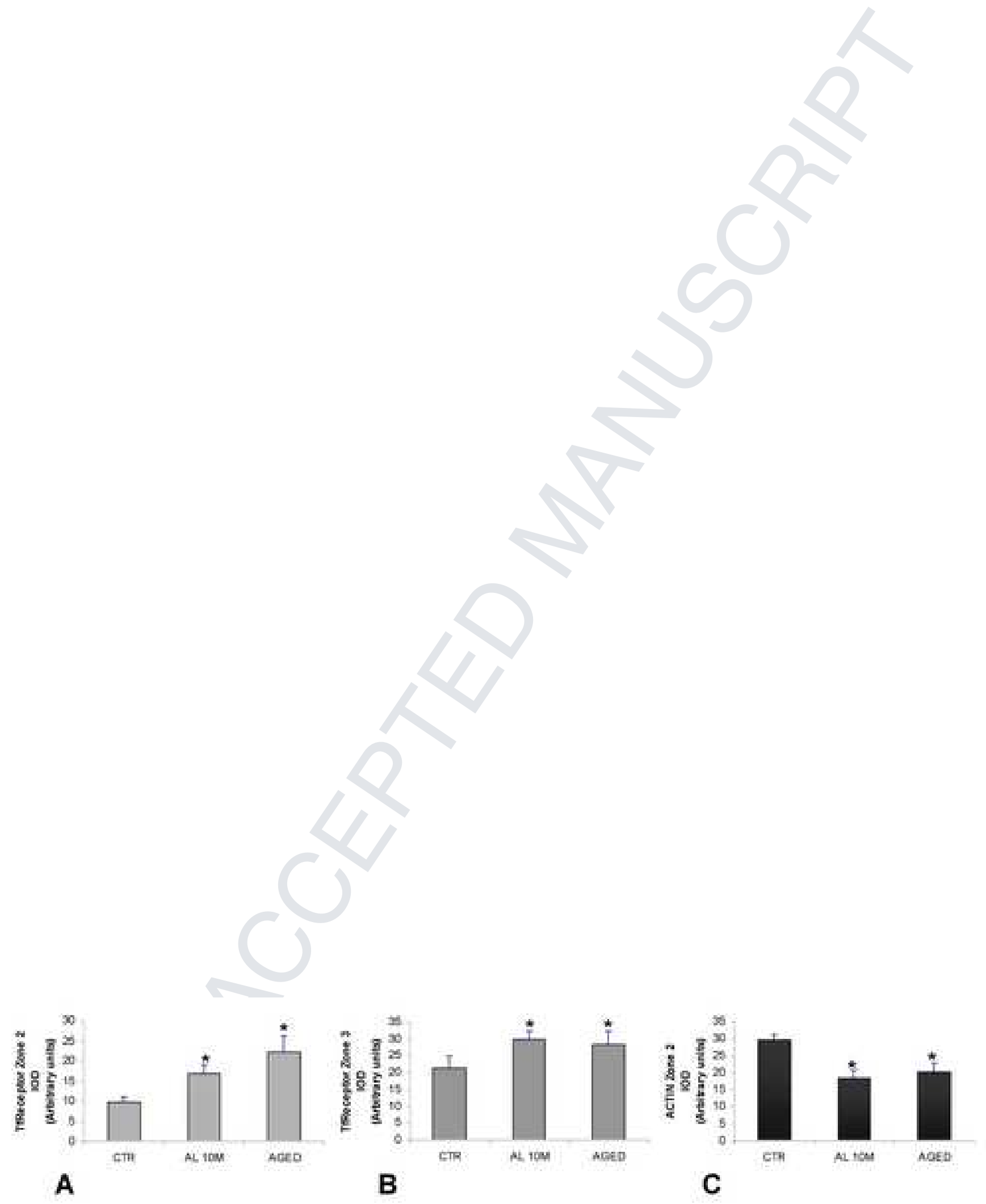



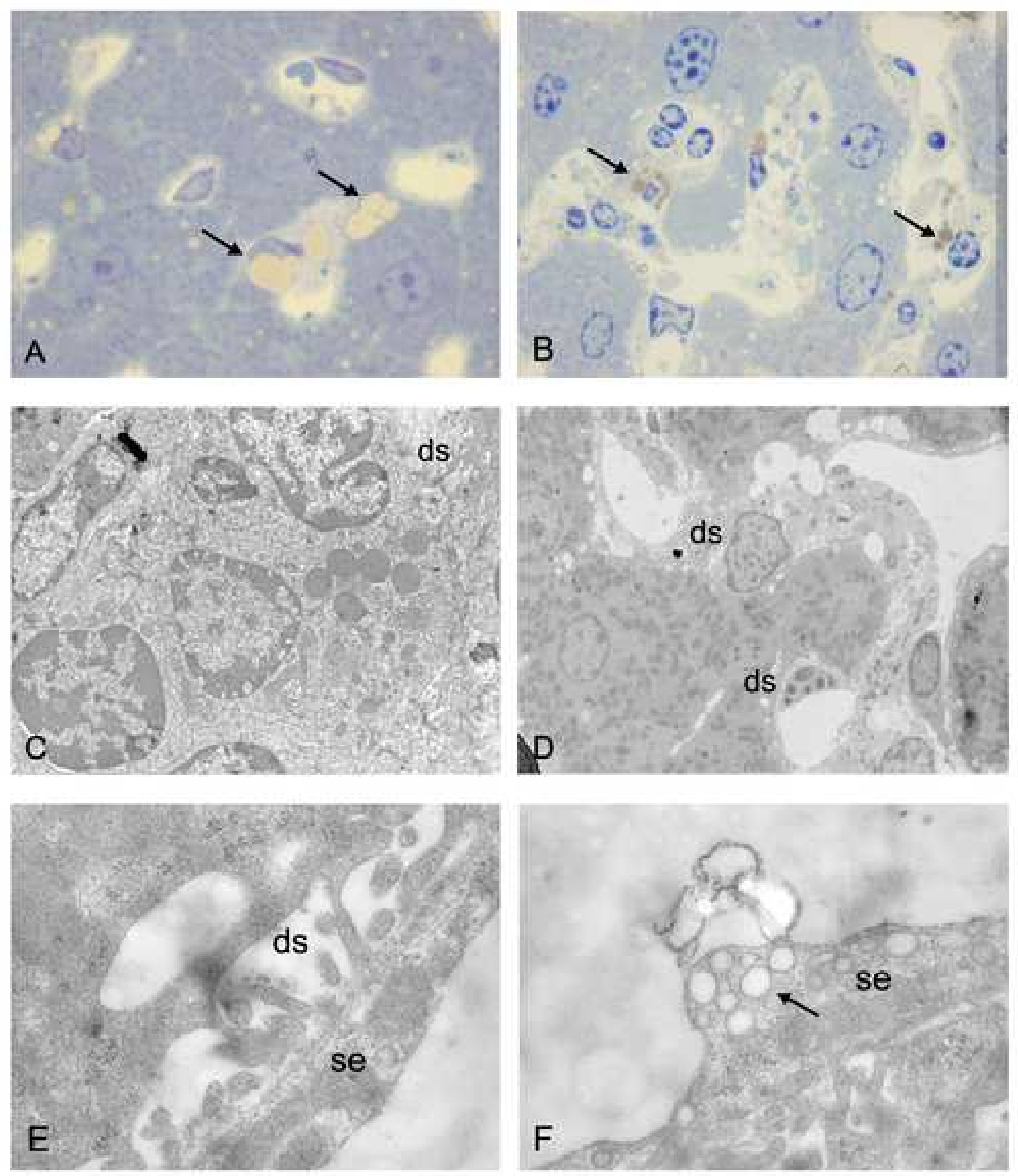

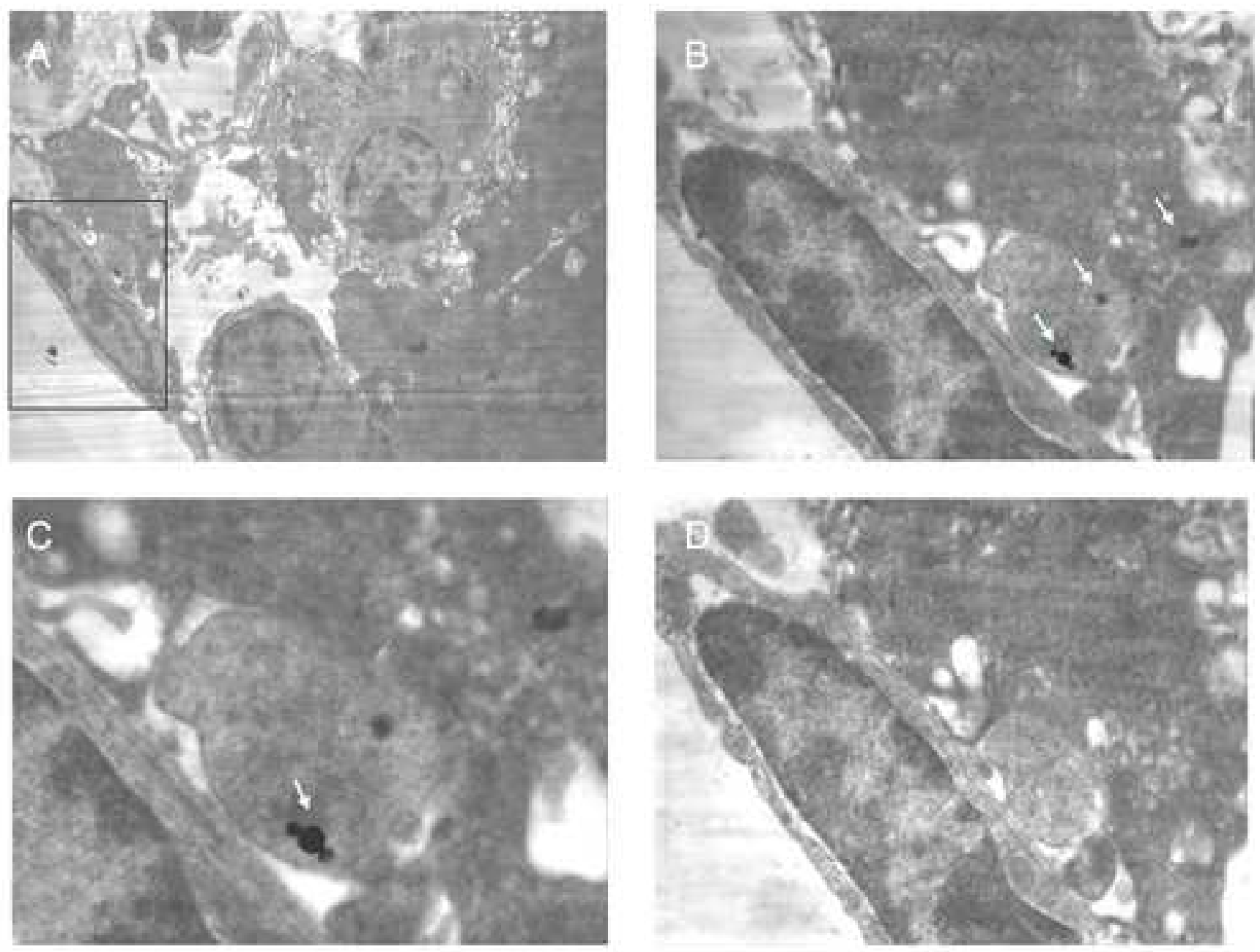


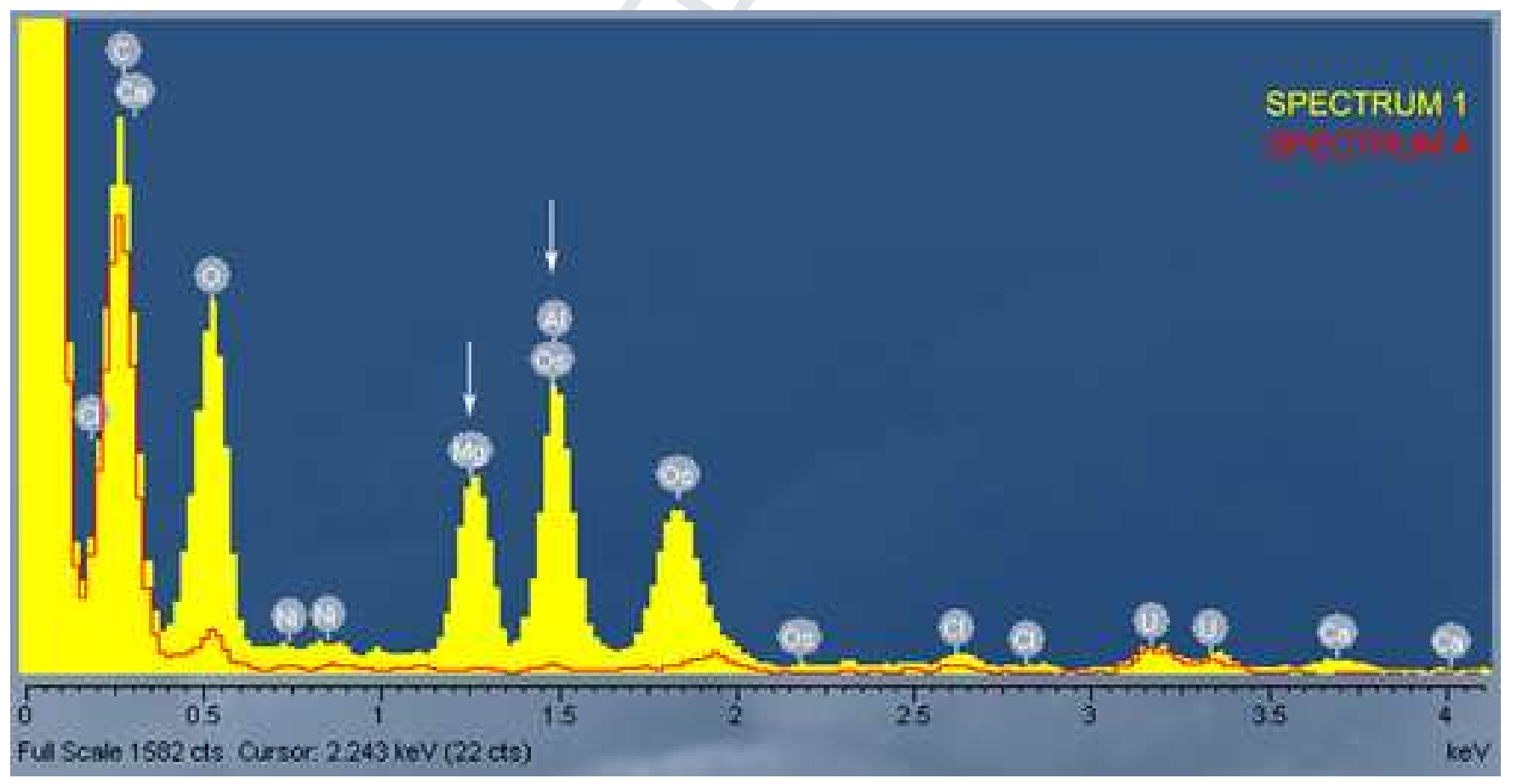

